\title{
Adapting English Newspapers to Develop Language Proficiency in Low-Level EFL Learners
}

\author{
Yi-chun $\operatorname{Pan}^{1}$ \\ ${ }^{1}$ Center for General Education, National Pingtung Institute of Commerce, Taiwan \\ Correspondence: Yi-chun Pan, Center for General Education, National Pingtung Institute of Commerce, Pingtung, \\ Taiwan 90004. E-mail: pan_yichun@yahoo.com
}

Received: June 7, 2014

Accepted: June 10, 2014

Online Published: June 20, 2014

doi:10.5430/elr.v3n1p66

URL: http://dx.doi.org/10.5430/elr.v3n1p66

\begin{abstract}
Students can increase their awareness of current events and develop into knowledgeable citizens of the world by reading the news. Authentic English news items, however, often contain difficult linguistic elements (including lexica and structures) that may prevent low-proficiency students from developing a genuine comprehension of the material, thus reducing this useful information to nothing more than a waste of paper. In order to provide students with lower levels of proficiency the opportunity to acquire more knowledge about the world while simultaneously improving their language abilities, this paper illustrates the adaptation of an authentic news item for low-proficiency learners. This research will identify the objectives of teaching an authentic news item, adapting and presenting it in a classroom environment, and will describe the student response to this instruction.
\end{abstract}

Keywords: Authentic news material, Adaption of authentic news items, Low-proficiency learners

\section{Introduction}

Monday's issue of the United Daily News features news items printed in English, courtesy of the New York Times, in addition to regular articles printed in Chinese. This English section provides a source for EFL teachers to use as a supplement to textbooks, which don't usually cover socio-cultural or real world information. It is generally believed that newspapers offer students with the opportunity to learn about the world while advancing their language abilities.

Authentic news material facilitates advanced learners' language proficiency; however, it is doubtful that unprocessed or non-adapted material will help low proficiency students to any significant extent. As an English teacher of low-level students at a vocational college, I often hear the following complaints: "The news items are too difficult. Almost every word is new to me," "I can't understand even one sentence, so I give up quickly," and "My teacher assigns at least two news items to read every week, but I can't even finish one paragraph. Those English news items don't do me any good." These complaints reflect a phenomenon that good reading material becomes garbage if it is not carefully processed just like good ingredients become disgusted meals if they are not prepared with care and attention.

The contents of the news can indeed increase students' awareness of current events and help them to become knowledgeable citizens of the world. It would be a pity if the difficult linguistic elements in authentic English news items (such as lexica and structures) prevented low-proficiency students from comprehending the material and the useful information was nothing more than wasted paper to them.

Low-level students are interested in knowing what's going on in the world, but unfortunately, the difficult wording in the English news puts them at a disadvantage. Teachers should always equip students with the tools they need. Adapting authentic material is one way that teachers can help low-porficiency learners overcome the reading challenges. In essence, adapting reading material means to simplify the language of a text without distorting or diluting its meaning. In this way, the content of the news can provide reinforcement for students the direct relationship between the language in the classroom and the outside world. At the same time, the simpler vocabulary and patterns maintain their interest in reading.

The following sections illustrate the adaptation of an authentic news item for low-proficiency students, identify the objectives of teaching this news item, presenting it in the classroom, and describe how students respond to the adapted news item instructed by the teacher. The original news item was published in the United Daily News, courtesy of the New York Times, on Monday, October 15, 2007. It is about an Okinawan protest against the distorted 
revision of history by the Japanese government.

\section{Adapting an Authentic News Item}

Based on the five criteria for the gradation of material, namely, pronunciation, lexica, collocation, grammar, and texture (Lin, 2007), the original material is suitable for advanced students. In order for low-porficiency learners to comprehend the text, the news item has been simplified in both vocabulary and grammar. The adapted version is in Appendix A.

There is no need to simplify the text's content. Rather, the goal is to make the material more accessible by eliminating a few linguistic features that impede comprehension. Material adaptation provides a bridge for students to read linguistically more complex information in the real world.

Wood (1998) has offered the following guidelines for adapting material:

1. Write shorter sentences. Make the sentences shorter. When you think the sentences are as short as they can possibly be, make them even shorter.

2. Simplify the vocabulary. If possible, use words that the students have already learned in class.

3. Simplify the grammar. For example, use the active voice instead of the passive voice. Also, use simple tenses, whenever possible.

4. Add additional language for clarification. In some cases, you will want to add language that clarifies the passage. You will have to reformulate the sentences to make them clearer.

5. Use cohesive devices (e.g., then, such, first, however, also). These words will give students a hint at the structure of the text. They clarify logical relationships between disparate elements. They are therefore critical in terms of the students' comprehension of the whole.

\section{Identifying Teaching Objectives for Adapted Material}

Before presenting adapted material in classrooms, teachers need to consider the objectives of teaching the reading material. The objectives involve two aspects: language and message (Nunan, 1999; Ur, 1996). Language refers to linguistic elements, which can be grammatical (for example, tenses and clause types), lexical and/or discoursal (for example, reference items, conjunctions, and linking expressions). Message, on the other hand, refers to the attitude, moral, value, etc. that teachers want to convey through the content.

In this case, there are two objectives for teaching this news item. In terms of language, subjunctive moods are the specific feature that teachers should familiarize students with. The Chinese and English languages are distinctive in their use of verbs when describing an event contradictory to the present or past facts. This difference has to be explicitly explained in class to minimize negative transfer. In addition, difficult words and phrases such as "grenade," "coerce," "stun," "initiate," "follow suit," etc should be taught and practiced to build up students' lexical power. Please refer to Appendix B for vocabulary and grammar exercises.

In terms of message, culture difference needs to be interpreted. EFL teachers should always keep the 'culture' issue in their mind, because learning a new language implies some degree of learning a new culture (Robinson-Stuart \& Nocon, 1996). Interpretation from teachers on cultural differences can enhance students' positive cross-cultural learning experiences and minimize negative culture shock (Robinson-Stuart \& Nocon, 1996).

As far as this news items is concerned, students might be startled to read how Okinawans committed mass suicide at the end of World War II. The Okinawans had been told by the Imperial Army soldiers that American troops would rape all the local women and run over the men with their tanks. In order to prevent being sexually assaulted or killed by the enemy, the Okinawans chose to kill themselves. Taiwanese students may find it difficult to imagine the fanatical patriotism of the Japanese at that point in history. This cultural difference needs to be interpreted.

Moreover, the Japanese were courageous to protest their government's distorted revision in textbooks. Japanese insistence on telling the truth is a positive value that we should teach to our generation. Many Taiwanese deal with unfairness or things that are unjust. It shouldn't be this way. We should strive to attain things that we deserve.

\section{Presenting Adapted Material in Classrooms}

Once teachers know what material they are going to teach, they must choose how they are going to teach it. To put it another way, at this stage, teachers should make an effort to present reading material that is not only comprehensible but interesting to students, who will then be more motivated to learn (Girard, 1977).

Brown (2007) suggests that teachers follow the three-part framework for teaching reading. In the pre-reading phase, 
teachers activate students' schemata by giving background information, introducing a topic, and outlining the purpose of the reading so that the students can more easily understand the text when they read it later. In the during-reading phase, teachers explain important linguistic elements to facilitate students' comprehension, and at the same time teach reading strategies such as skimming for the gist and scanning for a particular piece of information. In the after-reading phase, teachers can assign follow-up exercises to integrate reading skills with the other four skills, i.e., listening, speaking, writing, and translating (Lin, 2007).

The SQ3R technique is also an effective technique for use in a reading class (Robinson, 1970). Students first "survey" the text for an overview of main ideas. Then they ask "questions" about the text. After that, they "read" the text to look for answers to the previously formulated questions. In the "recite" stage, teachers guide students through the salient points of the text using either oral or written language. Finally, teachers design activities in the "review" stage to facilitate the embedding of what students have learned from the text into their long-term memories.

\section{Gauging Students' Response to the Adapted News Item}

In order to see the effect of adapted material, 10 low-proficiency students attended this lesson. When given the original news item, the ten low-achievers frowned and bemoaned the difficulty of the text. Ten minutes later, they were shown the adapted version, and several smiled. Eight students out of ten told me they could understand $70 \%$ of the text, compared with $10 \%$ when reading the original. It was clear that the simplified version facilitated comprehension.

I used the SQ3R techniques, illustrated in the previous section, to guide students to read this text. In order to activate their schema, they were requested to read questions I initiated in the exercises of 'Before You Read' and 'After You Read' (See Appendix B) before reading the text. After getting a general idea of what the news was about, they were asked to look for answers to questions. Meanwhile, I highlighted some difficult words and sentences that might result in the confusion of the meaning. Also, the cultural aspects were interpreted. Finally, the students were assigned to write on the following topic: "If I were the Okinawan, would I join the protest?" The dual purposes of this activity are to reinforce the grammar points of subjunctive moods, which are the key linguistic features in this news item, and to develop students' thinking as well.

\section{Conclusion}

The ten low-proficiency students were satisfied in the sense that they could read the newspapers. Even though the news item was adapted, not authentic, it was better than nothing. Students started to read something rather than just giving up at the beginning. Teachers should improve students' language proficiency with suitable material instead of scaring them away with content that is hard to understand. The limitations of this experiment were the low number of the participants was few and the short length of instructional time. Further research should involve a higher number of subjects and an extended period of time to conduct the experiment.

\section{References}

Brown, H. J. (2007). Teaching by principles: an integrative approach to language pedagogy. New York: Pearson Education.

Girard, D. (1977). Motivation: the responsibility of the teachers. ELT Journal, 31, 97-102. http://dx.doi.org/10.1093/elt/XXXI.2.97

Lin, C. C. (2007). Lectures. Tamkang University.

Nunan, D. (2001). Second Language Teaching and Learning. Beijing: Thomson Asia Pte Ltd.

Robinson, F. P. (1970). Effective study (4th ed.). New York: Harper \& Row.

Robinson-Stuart, G. \& Nocon, H. (1996). Second culture acquisition: ethnography in the foreign language classroom. Modern Language Journal, 47, 45-99.

Ur, P. (1996). A course in language teaching. Cambridge: Cambridge University Press.

Wood, J. W. (1998). Adapting instruction to accommodate students in inclusive settings. Upper Saddle River, NJ: Prentice Hall. 


\section{Appendix A: Simplified Version of the News Item}

The Reverend Shigeaki Kinjo is 78 years old and in declining health. He didn't want to talk about the tragic day 62 years ago, toward the end of World War II, when he beat his mother, younger brother and sister to death.

Brainwashed by Japanese Imperial Army soldiers into believing that American troops would rape all the women and kill all the men, Mr. Kinjo and others in his village thought that suicide was their only choice. A week before American troops landed and started the Battle of Okinawa in March 1945, Japanese soldiers gave the men in Mr. Kinjo's village two hand grenades each and taught them how to use one to kill Americans, and the other one to kill themselves.

Most of the grenades did not explode successfully, so a former district chief broke off a tree branch and used it to kill his wife and children. After watching this, Mr. Kinjo and his older brother followed suit; in other words, they did what the chief did, killing their own family members. 


\section{Appendix B: Reading Exercises}

\section{(A) Before You Read}

\section{Discuss the following questions with a partner.}

1. Look at the picture and the caption beside it. Why did so many people gather together in the picture?

2. Have you ever participated in a protest? Please share with your classmates what the protest was about and what your part in it was.

3. What would you do if China had been preventing Taiwan from joining the United Nations? Would you protest against China's actions?

4. The protest took place in Okinawa. What is Okinawa famous for?

\section{(B). After You Read}

Mark true statements with a $\mathbf{T}$ and false statements with an $\mathbf{F}$.

1. The mass suicides in Okinawa took place after the Second World War.

2. The mass suicide was due to the Japanese troops brainwashing the Okinawans, telling them that American troops would either rape women or run over men with trucks. Consequently, suicide was their only choice.

3. The Japanese government revises history textbooks based on the truths and facts.

4. The number of protesters is evidence that many Okinawans are enraged about the Japanese government's distorted history.

5. The Okinawan protest was the result of a strong disagreement with the Japanese government. Okinawans said the mass suicide was because of the Imperial Army troops, while the Japanese government was vague on the question.

\section{(C). Words in Context}

(I). Look at the list of the words from the reading. Match each word or phrase with a definition.

1. grenade $[\mathbf{g} \mathbf{r} \mathbf{I} \boldsymbol{n} \in \mathbf{d}]$

2. coerce $\left[\begin{array}{llll}\mathbf{K} & \mathbf{O} & \mathbf{S} & \mathbf{S}\end{array}\right]$

3. $\operatorname{stun}[\Im \mathrm{t} \cap \mathrm{n}]$

4. follow suit [ $T$ a $\perp O S \cup t]$

5. initiate [ $\mathbf{I}$ ' $\mathbf{I} \mathbf{I} \mathbf{I}, \mathbf{e} \mathbf{t}$ ]

a). to compel to an act or choice

b). to follow an example set

c). a small missile that contains an explosive or a chemical agent (as tear gas, a flame producer, or a smoke producer) and that is thrown by hand or projected (as by a rifle or special launcher

d). to overcome especially with paralyzing astonishment or disbelief

e). to cause or facilitate the beginning of

(II). Now complete the sentences below using words or phrases from (I). Be sure to use the correct form of the word.

1. Although are not as large as bombs, they are fatal and may cause many casualties.

2. The homeless man set himself on fire; the scene everyone who was there.

3. The mine owners the workers into going back to work by threatening to close down the mines completely.

4. The girl jumps over the fence, and her playmates

5. In terms of romance, Chinese men generally the first move, instead of women. 


\section{(D). Start Talking}

(I). Look at the conversation.

A: Why did the elderly woman no longer talk about her son?

B: Because he put her in a nursing home and then never visited her.

(II). Practice the conversation with a partner, using a fictitious reason as to why the mother didn't want to talk about her son.

\section{(E). Grammar Review}

(I). Use present unreal conditional sentences to talk about unreal, untrue, imagined, or impossible conditions and their results.

If Subject + were / Past tense verb..., Subject + would (should, could, might) + base verb...

- If I called my ex-boyfriend, my mother would beat me.

- If I had a dictionary, I could look up this word.

- If I were a rich man, I could buy a new car.

(II). Use past unreal conditional sentences to talk about past unreal, untrue, or imagined conditions and their unreal results.

$$
\text { If Subject + had pp ..., Subject + would (should, could, might) have pp ... }
$$

- If you had seen a doctor yesterday morning, you would have been able to sleep last night.

- If he had bought that dictionary, he could have learned those new words.

- If Jack had stayed here last night, he might have helped me with the work.

\section{(III). Match the two parts of the sentences}

Column A

1. I don't drive fast. However, I would drive as fast as necessary ...

2. My parents have a habit which I hate very much: opening my mail without my permission. If I were a parent, ...

3. School work occupies too much of my time. I would have more time to do the things I really like to do ...

4. My house need painting, but I have no money for it. If I were a painter, ...

\section{Column B}

a. ... I would allow my children to have their privacy.

b. ... if I didn't have to go to school so many days a week.

c. ... if I had to get someone to a hospital in an emergency situation.

d. ... I would do it on my own.

(IV). Write a passage of 100 words on the topic "If I were the Okinawan, would I join the protest? 